\title{
Tramadol Disposition in Neonates and Opioid Related Side Effects: The Route of Administration Matters
}

\section{Karel Allegaert ${ }^{1,2 *}$}

${ }^{1}$ Department of Development and Regeneration, University Hospitals Leuven, Belgium ${ }^{2} \mathrm{KU}$ Leuven and Neonatal Intensive Care Unit, University Hospitals Leuven, Belgium

Keywords: Developmental pharmacology; Pharmacogenetics; Ontogeny; Tramadol

We read the case series of Bilgili et al. on prolonged apnea and sedation in 3 former preterm babies after administration of oral tramadol (2 mg. $\left.\mathrm{kg}^{-1}\right)$ with great interest [1]. Although there may have been additional risks associated with the apnea and sedation events in these specific cases (e.g. low hematocrit, former preterm neonates), we confirm that these side effects were clinically significant and serious [1]. We reported on a similar, unanticipated side effect profile following low dose oral chloral hydrate administration in former preterm neonates for procedural sedation [2]. At least, such observations confirm that prospective studies are urgently needed to improve the effect/side effect balance of analgesic treatment in neonates. Consequently, the authors need to be congratulated for both their effort to perform the study and report the unanticipated side effects. As a neonatologist and clinical pharmacologist with clinical and research experience with this compound in neonates, I would like to draw the attention of the readers and authors to a likely pathogenetic explanation of these events since this likely relates to tramadol metabolism and its routes of elimination.

Tramadol (M) is metabolized by O-demethylation (cytochrome P450 [CYP] 2D6) to the pharmacodynamic active metabolite O-demethyl tramadol (M1). Compared to the mother compound, M1 has a much higher affinity for the $\mu$-opioid receptor and has much more potent analgesic effects [3-5]. This metabolite is subsequently eliminated by renal route while $\mathrm{M} 1$ hepatic/enteral synthesis depends on ontogeny, i.e. age-dependent activity of the CYP2D6 enzyme and CYP2D6 polymorphisms $[4,5]$. Consequently, the $\mathrm{M} 1$ plasma concentration will be the main driver for both opioid related effects and side-effects and it is very likely that the side effects relate to the phenotypic M1 plasma concentration while the M1 plasma concentration depends on, in part the maturational stage of these former preterms, but also in part to the oral route applied $[6,7]$.

Firstly and as recently published, the hepatic/enteral versus renal pathway do not mature simultaneously in early life. Tramadol plasma time-concentration profile changes with postmenstrual age. At term equivalent age, the hepatic/enteral capacity to produce M1 is already more mature compared to the renal capacity to eliminated M1 [4,5]. Consequently, M1 accumulation may occur and may result in opioid related side effects. In addition, the individual CYP2D6 polymorphisms further affects the M1 production [4,5].

Secondly-and different compared to the intravenous route we described -tramadol was administered by oral route [1], resulting in additional first pass hepatic/enteral effects compared to the intravenous route. In general, the first pass effect will result in metabolism of the mother compound to a metabolite at the intestinal brush border or in the liver through the portal venous circulation. For tramadol, this will result in a higher production of M1 and subsequent M1 exposure. Once again, the maturational changes in early life will result in a proportionally higher M1 production as documented in a longitudinal study on oral dextromethorphan disposition in the first year of life [8]. The CYP2D6 enzyme activity (O-demethylation) matures faster [8].
Based on the available observations in literature, we claim that the side effects observed were likely due to a higher conversion of tramadol to M1 and can be explained based on metabolic ontogeny (maturational activity of CYP2D6, hepatic and intestinal), renal ontogeny (maturational renal clearance), and the route of administration (oral instead of intravenous, higher first pass effect with higher M1 production) [4,5,8]. An additional explanation may be that these 3 former preterm neonates had a CYP2D6 'ultrafast metabolizer' polymorphism [4].

The only way to learn more about these maturational changes in both pharmacokinetics and -dynamics of analgesics, is to conduct prospective studies that collect both information on population specific pharmacokinetics (concentration-time profile) and -dynamics (concentration-effect profile) [6,7].

\section{Acknowledgements}

Karel Allegaert is supported by the Fund for Scientific Research, Flanders (Fundamental Clinical Investigatorship 1800209N). There are no conflicts of interest to report.

\section{References}

1. Bilgilli B, Bozkurt I, Bozkurt P, Metin F (2012) Prolonged apnea and sedation in premature babies with the use of oral tramadol. J Clin Case Rep 2: 1-3.

2. Allegaert K, Daniels H, Naulaers G, Tibboel D, Devlieger H (2005) Pharmacodynamics of chloral hydrate in former preterm infants. Eur J Pediatr 164: 403-407.

3. Bozkurt $P(2005)$ Use of tramadol in children. Paediatr Anaesth 15: 1041-1047

4. Allegaert K, van Schaik RH, Vermeersch S, Verbesselt R, Cossey V, et al (2008) Postmenstrual age and CYP2D6 polymorphisms determine tramado o-demethylation in critically ill neonates and infants. Pediatr Res 63: 674-679.

5. Allegaert K, Rochette A, Veyckemans F (2011) Developmental pharmacology of tramadol during infancy: ontogeny, pharmacogenetics and elimination clearance. Paediatr Anaesth 21: 266-273.

6. Smits A, Kulo A, de Hoon JN, Allegaert K (2012) Pharmacokinetics of drugs in neonates: pattern recognition beyond compound specific observations. Curr Pharm Des.

7. Allegaert K, Verbesselt R, Naulaers G, van den Anker JN, Rayyan M, et al. (2008) Developmental pharmacology: neonates are not just small adults... Acta Clin Belg 63: 16-24.

8. Blake MJ, Gaedigk A, Pearce RE, Bomgaars LR, Christensen ML, et al. (2007) Ontogeny of dextromethorphan $\mathrm{O}$ - and $\mathrm{N}$-demethylation in the first year of life. Clin Pharmacol Ther 81: 510-516.

*Corresponding author: Karel Allegaert, MD, PhD, Neonatal Intensive Care Unit, University Hospital, Herestraat 49, 3000 Leuven, Belgium, Tel: 00-32-16-343850; Fax 00-32-16-343209; E-mail: karel.allegaert@uzleuven.be

Received November 17, 2012; Accepted January 18, 2013; Published January 21, 2013

Citation: Allegaert K (2013) Tramadol Disposition in Neonates and Opioid Related Side Effects: The Route of Administration Matters. J Clin Case Rep 3: 246 doi:10.4172/2165-7920.1000246

Copyright: (c) 2013 Allegaert K. This is an open-access article distributed under the terms of the Creative Commons Attribution License, which permits unrestricted use, distribution, and reproduction in any medium, provided the original author and source are credited. 